\title{
A Discounting Framework for Regulatory Impact Analysis
}

\author{
ROBERT W. STAIGER and BARBARA C. RICHARDSON \\ Transportation Planning and Policy, Urban, Technological, and Environmental Planning Program, \\ Horace H. Rackham School of Graduate Studies, The University of Michigan, 506 E. Liberty, \\ Ann Arbor, MI 48104, U.S.A.
}

\begin{abstract}
This article presents a methodology designed to facilitate the systematic comparison of alternative discounting procedures for the costs and benefits of industrial regulatory activity. A discounting framework developed by Bradford is adapted for use in the context of industry regulation. Within this framework, the choice among the various discounting procedures is reduced to a choice between assumptions about various economic and financial parameter values. As an illustration of the way in which the framework can be applied, the article includes an examination of the validity of parameter assumptions implied by the discounting approach currently used by regulatory agencies in their analyses of regulations affecting the motor vehicle industry. Several hypothetical programs are analyzed to demonstrate the broad differences in program treatment that might be expected if this current discounting approach were replaced by procedures generated within the framework from more reasonable parameter assumptions. Sensitivity of the benefit/cost calculations to uncertainty about underlying parameters is also briefly discussed.
\end{abstract}

\section{Introduction}

The time path of regulatory costs and benefits is an important consideration in determining the net worth of regulatory activity to society. Since the benefits and costs of compliance with a particular standard generally occur at different points in time, the weights attached to benefits and costs in each time period - that is, the discounting procedure - will often play a decisive role in determining whether a particular regulatory activity should be undertaken.

Discounting facilitates comparison between cost and benefit streams that have different time profiles by collapsing future costs and benefits into present value equivalents that is, valuing all costs and benefits at a single reference point in time, normally the present. The need for such an adjustment follows simply from the fundamental observation that the perceived value today of having a (real) dollar today is in general greater than the perceived value today of having a (real) dollar at some fixed date in the future. 
Though the need for adjusting the value of a dollar to reflect this time dimension is clear, the correct method of adjustment when public projects are involved is a complex issue. It continues to be a matter of controversy among economists, so much so that the U.S. Office of Management and Budget (OMB) has chosen to sidestep the theoretical debate and has suggested, in its guidelines for regulatory impact analyses (1981), the use of a 10 percent real rate of discount for costs and benefits of all regulatory activity. In a partial acknowledgement of the underlying debate, the guidelines state that alternative discount rates, where justified, are to be used to perform sensitivity analysis.

With regard to regulatory impact analyses for the motor vehicle industry, the $10 \%$ rule and accompanying sensitivity analysis has been combined with a "cost-to-consumer" approach for estimating the costs of regulatory activity. The cost-to-consumer (c-t-c) approach is based on the premise that the direct resource costs of a regulation are best measured by its price impact on the products of the regulated industry. By measuring costs in this manner, the costs and benefits of a proposed regulation are discounted using the $10 \%$ rule. Sensitivity analysis, when it has been done, is accomplished by varying the discount rate around this 10 percent level.

It is, however, impossible to proceed with a proper sensitivity analysis without some notion of the assumptions that underlie the $10 \%$ rule/c-t-c procedure and the uncertainty that is associated with those assumptions. Without such information, it is not clear that the $10 \%$ rule/c-t-c approach represents a "best guess" at the appropriate discounting procedure, nor is it clear what would constitute a reasonable range of parameter values for the purpose of sensitivity analysis. Thus, for example, in the absence of a clear and explicit definition of what the discount rate in the OMB procedure is supposed to represent, there is no basis upon which to judge the merits of requiring the use of a value of 40 percent as the "best estimate" - best estimate of what? - nor is there any meaningful way to choose a range of discount rates that ought reasonably to be considered in the sensitivity analysis. It is the aim of this article to provide a framework within which the assumptions underlying discounting procedures such as the $10 \%$ rule/c-t-c approach become explicit, and within which reasonable alternative procedures can be meaningfully derived.

The remainder of this article proceeds as follows. First, the issues involved in selecting a discounting procedure for public investment projects are examined, and a short description of the major competing views expressed in the literature is provided. Next, a discounting framework developed by Bradford (1975) is described. It is particularly well-suited to serve as a vehicle for comparison of the competing views in the literature, since it reduces to each of the major discounting procedures under appropriate parameter assumptions. Finally, the Bradford framework is disaggregated and adapted to the costs and benefits of industry regulation. The resulting framework could in principle be applied to generate reasonable discounting procedures for the costs and benefits of any form of industrial regutlatory a activity. As an illustration, the framework is employed to evaluate the $10 \%$ rule/c-t-c approach used in regulatory impact analyses for the motor vehicle industry. 
In order to address the difference between the present value of a dollar held this period and a dollar held next period, a discounting procedure must contain information about the generally available rate of return on funds. Consequently, the notion of discounting is tied fundamentally to the measurement of opportunity costs - the value of the resources in their best alternative use. A proper discounting procedure will ensure that the return on the resources employed in any undertaking is at least as high as the return available in any feasible alternative use.

It is well-accepted that the optimal rate of discount for private sector investment projects should reflect the returns available to the owners of the firm on alternative investments of equal risk [1]. Thus, for private sector investment projects, the real rate of discount is clearly the real (private) opportunity cost of capital to the firm, denoted $r$. It follows that the firm should undertake any investment project for which [2]

$$
\sum_{t=0}^{T} \frac{1}{(1+r)^{t}}\left[B_{t}-C_{t}\right]>0
$$

where:

$$
\begin{aligned}
& B_{t}=\text { real benefits (returns on investment) accruing to the firm in period } t \\
& C_{t}=\text { real costs of the investment project incurred by the firm in period } t, \\
& T=\text { duration of investment project, and } \\
& r=\text { opportunity cost of capital to the firm. }
\end{aligned}
$$

Following this investment criterion, the firm will never allocate funds to a project whose return is less than what those funds could generate in some alternative feasible use.

However, as pointed out by Baumol (1968), the optimal rate of discount for public sector investment projects is complicated by two apparently conflicting optimality criteria that involve both the opportunity cost of capital to the firm and the rate at which society is willing to trade present consumption for future consumption, or society's rate of time preference.

On the one hand, if the government's objective is to achieve an efficient allocation of resources between the private and public sectors, it must not tax investment funds away from the private sector in order to undertake a public investment project whose real return is below that available from private sector investment. This suggests that the real rate of return available in the private sector, $r$, should be incorporated into the public project discounting procedure whenever funds for the public project in question would otherwise be invested by the private sector.

On the other hand, if the government wishes to serve the time preferences of society and acknowledges the existence of a (real) rate, $i$, at which society is just willing to trade consumption now for consumption in the future, then a public project whose funding comes at the expense of foregone private consumption should be undertaken if and only 
if its return is at or above the social rate of time preference. This suggests that the social rate of time preference, $i$, should be incorporated into the public project discounting procedure whenever funds for the public project in question would otherwise be consumed by society.

In other words, where public projects are concerned, it appears that both the social rate of time preference, $i$, and the opportunity cost of capital, $r$, must be incorporated into the discounting framework [3]. Only by using such a framework can the government, on the one hand, hope to avoid taking funds away from the private sector in order to launch a public project whose return to society is less than what those funds would have generated in their alternative private sector use, and on the other, hope to avoid rejecting a public undertaking that would have actually improved society's well-being.

The issue, then, is not whether to include both the opportunity cost of capital and the social rate of time preference in the public project discounting framework, but rather how best to include them. Two characteristics of the U.S. economy guarantee that this is not a trivial issue [4].

First, the government faces constraints on its investment opportunities that prevent it, in general, from taxing private consumption and simply investing those revenues freely in the private sector. If the government were able to do this freely, then all private investment opportunities would be public investment opportunities as well. In this case, only the rate of return on private capital would be relevant for the public investment decision, since it would represent the true opportunity cost of those funds. If a potential "public" project were to produce a lower rate of return than that prevailing in the private sector, then the "public" project would be rejected, and the government would instead invest those funds in a "private" sector undertaking. Since the government does not, in practice, have unlimited access to private sector undertakings, this simple answer is not justified [5].

Second, the issue itself would not arise in an undistorted economy with perfect capital markets, since only one relevant market rate of interest would exist, at once representing the opportunity cost of capital and the social rate of time preference. However, in reality, a host of taxes (and other distortions) on the income from capital and on the yields from savings forces the opportunity cost of capital above, and the social rate of time preference below, the undistorted market rate of interest.

Moreover, the wedge between these two market rates is quantitatively substantial. While estimates of the real social rate of time preference lie in the 3 to 6 percent range, estimates of the real opportunity cost of capital range from 10 to 25 percent (Tresch 1981). Thus, the contradiction to which Baumol refers raises a quantitatively important question: How should the discounting framework for public projects incorporate both the opportunity cost of capital in the private sector and the social rate of time preference?

\section{The Literature}

On this question, three well-defined groups have emerged in the literature. One group 
[the opportunity cost approach - e.g., Harberger (1972), Baumol (1968), Sjaastad and Wisecarver (1977), Sandmo and Dreze (1971), and Mishan (1976)] sees the rate of discount on public investment as fundamentally an opportunity cost, reflecting the returns available in the best alternative use. Hence, it is the discount rate itself which should reflect information about $i$ and $r$. Even without this group, there remains considerable disagreement over:

- which alternative investments are truly available to the government,

- the operational definition of returns, and

- empirical estimates, even when interpretations of the above points are agreed upon.

However, despite such disagreements over just what the true opportunity costs of public investment funds are, economists in this group agree that it is the discount rate, and the discount rate alone, that must be adjusted to account for these opportunity costs.

A second group [the time preference/shadow price approach - e.g., Marglin (1963a, 1963b), Arrow (1966), and Feldstein (1972)] views the discount rate for public investment as simply the rate at which society is willing to trade consumption at present for consumption in the future, the social rate of time preference. Net benefits from a public project should be treated as additions to the stream of consumption available to society, and should be discounted in the manner that society would discount the value of any consumption stream. This group acknowledges the importance of the opportunity cost of funds, but argues that this opportunity cost is properly accounted for, not by adjusting the discount rate, but by applying an appropriate shadow price - a price which reflects the true social valuation - to investment costs of the project.

A third group [e.g., Diamond (1968), Diamond and Mirrlees (1976), McKean (1958)] maintains that it is pointless to attempt to associate the rate of discount for public projects with either opportunity costs or social time preference. They view the rate of discount on public projects as simply one shadow price among many in the second-best (distorted) environment which will depend, as do all shadow prices, on the nature and extent of those distortions.

While the view represented by Diamond and McKean may be the most satisfying on strictly theoretical grounds, it is not, by itself, particularly helpful in developing policy guidelines except that it suggests a criterion upon which to evaluate the existing operational discounting procedures. Since the appropriate form for a discounting procedure ultimately depends on the environment within which it is to be applied, and since differences in the major discounting procedures can be traced to differences in underlying assumptions, the validity of a discounting procedure for use in a particular situation may be judged by the validity in that situation of the assumptions underlying the procedure. In the next section, a framework is presented which facilitates the evaluation of alternative discounting procedures through the comparison of the assumptions that underlie them. 


\section{Analysis}

The Bradford Framework

In his 1975 article, Bradford presents a very general analytical framework which he uses to derive a discounting procedure for public investment programs. The framework is general enough to include the major competing discounting procedures(i.e., opportunity cost and time preference/shadow price approaches) as special cases, and is used here as a vehicle to facilitate comparison of the several alternatives.

Bradford begins with an explicit statement of the government's constrained optimization problem. He first assumes that the government's objective in undertaking public investment projects is to maximize the discounted stream of aggregate consumption over time, where the discount rate is the social rate of time preference. While governments may have distributional goals as well, these are achieved by redistributional actions which are assumed to be separate from government investment decisions [6].

Next, Bradford defines the shadow price of private capital, $V_{t}$, as the present value of the stream of consumption, discounted at the social rate of time preference, that is created by one dollar of private investment at time $t$. To clarify the meaning of this important concept, Bradford writes:

... imagine that a unit of time $t$ capital drops like manna from heaven, affecting the whole stream of consumption starting at time $t+1$. In this new consumption stream, by how much at most could one reduce the amount of cunsumption in period $t$, and still have a consumption stream as valuable (according to the government preferences) as the original, pre-manna, consumption stream? The answer is $V_{l}$, and in this sense, $V_{t}$ is the social value of a unit of private capital at time $t$.

Finally, Bradford assumes a second-best world in which government investment is restricted to certain classes of activity. The idea is that where private investment opportunities are not also public investment opportunities, the rate of return on these private projects does not represent the true opportunity cost to the goverment. Specifically, it is assumed that the government cannot redistribute funds from consumption to saving by simply taxing consumption and investing those funds freely in the private sector. Hence, to the extent that funds for a potential public project do come from private consumption, the private rate of return, $r$, does not represent the opportunity cost for these funds and therefore should not enter into the public investment decision.

Given $V_{t}$ and the explicit statement of the government's constrained optimization problem, the public investment decision framework is derived simply by calculating the present discounted value of the gains and the losses in consumption (discounted at the social rate of time preference) that would result from the public project, and determining whether the former is larger than the latter. Specifically, let

$a_{t}=$ the fraction of each dollar of government investment that comes at the expense of private investment at time $t$, 
$\alpha_{t}=$ the fraction of each dollar of benefits from the public project that is saved (invested) at time $t$,

$V_{t}=$ the present value of the stream of consumption, discounted at the social rate of time preference, that is created by one dollar of private investment at time $t$,

$C_{t}=$ the total dollar value of the project costs (expenditure) at time $t$,

$B_{t}=$ the total value of the project benefits at time $t$,

$i=$ the social rate of time preference,

$T=$ the period in which the last project payment or return occurs,

$L_{c}=$ loss in discounted consumption caused by the public project, and

$G_{c}=$ gain in discounted consumption accruing from the public project.

Then,

$$
\begin{aligned}
& L_{c}=\sum_{t=0}^{T} \frac{1}{(1+i)^{\prime}}\left[\left(1-a_{t}\right)+a_{t} V_{t}\right] C_{t} \\
& G_{c}=\sum_{t=0}^{T} \frac{1}{(1+i)^{t}}\left[\left(1-\alpha_{t}\right)+\alpha_{t} V_{t}\right] B_{t}
\end{aligned}
$$

and $G_{c}>L_{c}$ implies

$$
\sum_{t=0}^{T} \frac{1}{(1+i)^{t}}\left\{\left[\left(1-\alpha_{i}\right)+\alpha_{t} V_{t}\right] B_{t}-\left[\left(1-a_{t}\right)+a_{t} V_{t}\right] C_{t}\right\}>0
$$

The expression in brackets in Equation (2) represents the division of one dollar project costs into

- direct consumption losses caused by project funding occurring at time $t,\left(1-a_{t}\right)$, and

- the present discounted value of indirect consumption losses occurring from displaced investment as a result of project funding at time $t, a_{t} V_{t}$.

The bracketed expression in Equation (3) represents the division of one dollar of project benefits into

- direct consumption gains resulting from project benefits occurring at time $t,\left(1-\alpha_{t}\right)$ and

- the present discounted value of indirect consumption gains occurring from increased investment as a result of project benefits at time $t, \alpha_{t} V_{t}$.

The bracketed terms in Equations (2) and (3) are thus the adjustment factors reflecting the discounted consumption value to society of one dollar of public project costs and benefits, respectively. These terms explicitly acknowledge the fact that, in the second best environment assumed, the source of funds and destination of benefits will affect the social valuation of a public program. Specifically, since the divergence between $r$ and $i$ results in a lower amount of private savings and investment in the economy than is 
socially optimal, government investment projects which increase net total private investment in the economy are socially more beneficial, all else being equal, than government investment projects which decrease net total private investment in the economy. Thus, in Expression (4), the higher $\alpha_{t}$ is relative to $a_{t}$, the greater is the net increase in private investment that would result from the public project under consideration, and hence, the greater is the likelihood that $G_{c}$ will be larger than $L_{c}$.

Note that, in the special case where the project is funded out of resources that otherwise would have been consumed and provides benefits which are consumed as they accrue, $\alpha_{t}=a_{t}=0$, and Expression (4) simplifies to

$$
\sum_{t=0}^{T} \frac{1}{(1+i)^{t}}\left[B_{t}-C_{t}\right]>0
$$

In this case, the project simply postpones consumption to some future date, and to be worthwhile, must provide a rate of return which is at least as high as the rate, $i$, at which society is willing to postpone consumption now for consumption in the future.

That the source of project funds and destination of project benefits - that is, the distinction between displaced (replaced) investment and displaced (replaced) consumption - should affect the valuation of a public project is agreed upon by all who acknowledge the second-best characteristic that the class of investment projects from which the government may choose is (artificially) limited [7]. However, as discussed above, the method of accounting for source and destination is a matter of debate among public sector economists. Fortunately, the Bradford framework as presented in Expression (4) is general enough to include each of the competing discounting approaches as special cases, and can thus be used as a vehicle for this debate. Couched in this framework, the debate reduces to one over the true values of various economic and financial parameters.

\section{Difference in Assumptions}

Although the validity of both the opportunity cost approach and the time preference/ shadow price approach depends on several important assumptions, Sjaastad and Wisecarver (1977) have recently shown that the controversy between the two approaches can be traced to different assumptions about the treatment of public capital depreciation. Specifically, they demonstrate that the time preference/shadow price approach (as represented by Marglin) assumes implicitly that society does not differentiate between net and gross returns on public investment projects. Thus, both depreciation and net benefits from the public project are subjected to the same savings/consumption decision. This implies, in terms of the Bradford framework, that the parameter $\alpha_{t}$ in Expression (4) must assume only one value regardless of whether benefits represent depreciation or net returns on the public investment project.

The validity of the opportunity cost approach, on the other hand, rests on the 
assumption that as the public investment project depreciates, society uses the benefits which represent depreciation of public capital to replace the private capital which had been displaced by the original funding of the public investment. In terms of the Bradford framework, this implies that, while the parameter $\alpha_{t}$ is free to assume any value for benefits that represent net returns to the public project, it must assume a value equal to the parameter $a_{t}$ for project benefits which represent depreciation of public capital. Sjaastad and Wisecarver propose three assumptions that will ensure this result:

- society can and does recognize the difference between depreciation and net benefits from a public investment project,

- society attempts to save all of the benefits from the public project which represent depreciation, and

- through the interest rate effects of a properly functioning capital market, society ends up saving exactly that amount necessary to restore private investment to its original (pre-project) level, once the public investment has fully depreciated.

The three assumptions made by Sjaastad and Wisecarver represent sufficient, but not necessary, conditions to ensure the savings behavior that is required for the opportunity cost approach to be the appropriate discounting procedure. Ultimately, the choice between the opportunity cost approach and the time preference/shadow price approach depends simply on how society treats depreciation of the public capital in question. If society saves in such a way as to replace the displaced private investment as the public capital depreciates, then the opportunity cost approach is the more appropriate discounting procedure. If society does not save in this manner, but instead subjects depreciation and net benefits from the public project to the same savings/consumption decision, then the time preference/shadow price approach is more appropriate.

\section{The Disaggregated Bradford Framework}

When examined within the Bradford framework, the debate between the opportunity cost and time preference/shadow price approaches turns out to be one over the appropriate level of aggregation of project costs and benefits. Specifically, the opportunity cost approach argues for a level of disaggregation sufficient to allow for differential saving behavior (of a specific form) between benefits which represent net benefits, and those which represent depreciation of public capital. Fortunately, the Bradford framework is amenable to disaggregation of project costs and benefits, and can be expressed in a manner capable of handling different types of costs and benefits accruing to any number of different groups.

Within this disaggregated framework, the Bradford model will reduce to the various opportunity cost methods (represented in the literature) under certain assumptions for its parameter values and to the various time preference/shadow price approaches under other parameter assumptions. The disaggregated framework not only incorporates the opportunity cost models and the time preference/shadow price models as special cases, 
but allows explicit treatment of the more general question which Sjaastad and Wisecarver raise: Are there any important differences in savings behavior which the aggregation of benefits and costs denies?

Since the essence of Bradford's approach is to evaluate the net change in society's consumption stream that would result from the government project under consideration, what is required in the context of industry regulation is a simple representation of the way in which industrial regulatory activity might affect society's aggregate consumption: Thus, in order to disaggregate the Bradford framework and apply it to the costs and benefits of industry regulation, it is necessary to isolate those points at which a savings/ consumption decision must be made as a result of the regulation, and to assign parameter values ( $\alpha$ 's and $a$ 's) which characterize the decision in each case.

Consider the following stylized characterization of the impacts of a regulatory project. Initially, all costs of compliance with a regulation will be born by the ind ustry [8]. While for generality, the framework could allow the fraction of each dollar of initial expenditure which displaces investment to be determined exgenously, it is clear that this initial expenditure must come purely at the expense of private investment. Firms in the industry must either initiate the project with internal funds or with funds borrowed from external sources. In the former case, the firm must forego its own private undertakings to comply with the regulatory demands [9]. In the latter case, the funds for the regulatory activity are borrowed in private capital markets. In either case, the initial funds for the project come at the expense of private investment, and should be valued accordingly.

Over time, the industry will attempt to pass these costs on to the consumer and, in so doing, will recover part or all of the costs incurred as a result of the regulation - this will serve to replace the private investment displaced by the original regulatory expenditure as well as a return on the initial investment, which results in a revenue allocation decision on the part of the firm. The recovery of these costs also results in a savings/consumption decision on the part of the consumer who must decide whether to meet these costs via foregone consumption or by reducing savings. Finally, consumers are also receiving the benefits of the regulation, which may be saved or consumed in the proportion desired. In order to allow for the possibility of the kind of savings behavior envisioned by Sjaastad and Wisecarver, benefits can be broken down into those representing net returns of the project and those representing depreciation of public capital.

With the explicit introduction into the Bradford framework of each of the major consumption/savings decisions that occur along the dynamic cost-pass-through process from industry to consumer, and assuming that the parameters - $\alpha$ 's, $a$ 's, and $V-$ are constant over time, the original framework presented in Expression (4) can be restated as:

$$
\begin{aligned}
& \sum_{t=0}^{T} \frac{1}{(1+i)^{l}}\left\{B_{t}^{d}\left[\left(1-\alpha^{b d}\right)+\alpha^{b d} V\right]+B_{t}^{n}\left[\left(1-\alpha^{b n}\right)+\alpha^{b n} V\right]-\left[V C_{t}+R_{t}^{d}\left[\left(a^{r d}-1\right)(V-1)\right]+\right.\right. \\
& \left.\left.R_{t}^{n}\left[\left(a^{r n}-\alpha^{r n}\right)(V-1)\right]\right]\right\}>0
\end{aligned}
$$


where

$B_{t}^{d} \quad=$ benefits of the public project that are viewed as depreciation at time $t$,

$B_{i}^{n} \quad=$ benefits of the public project that are viewed as net returns at time $t$,

$C_{t}=$ the total dollar value of the project's costs at time $t$,

$R_{t}^{d} \quad=$ industry revenue representing depreciation of the regulatory investment project (price impact per vehicle associated with recovery of depreciation on regulatory investment costs times number of vehicles affected),

$R_{i}^{n} \quad=$ industry net revenue from the regulatory project (price impact per vehicle associated with the recovery of net returns on regulatory investment times number of vehicles affected),

$\alpha^{b d}=$ the fraction of each dollar of public project benefits viewed as depreciation that is saved (invested),

$\alpha^{b n}=$ the fraction of each dollar of public project benefits viewed as net returns that is saved (invested),

$\alpha^{r n} \quad=$ the fraction of each dollar of revenues representing the recovery of net returns on investment that is saved (invested), and

$a^{r d}, a^{r n}=$ the fraction of each dollar of revenues representing the recovery of depreciation and net returns on investment, respectively, that comes at the expense of private (consumer) saving.

An additional simplifying assumption that makes Expression (6) potentially more useful, as it reduces the data required to make it operational, is that $R_{t}^{n}$, the net return from the regulatory investment captured by the industry, is approximately zero. Under this simplifying assumption, Expression (6) can be rewritten as

$$
\begin{aligned}
& \sum_{t=0}^{T} \frac{1}{(1+i)^{t}}\left\{B_{t}^{d d}\left[\left(I-\alpha^{b d}\right)+\alpha^{b d} V\right]+B_{t}^{n}\left[\left(1-\alpha^{b n}\right)+\alpha^{b n} V\right]-\right. \\
& \left.\left[V C_{t}+R_{t}\left[\left(a^{r d}-1\right)(V-1)\right]\right]\right\}>0
\end{aligned}
$$

where

$R_{t} \quad=$ total industry revenues associated with the regulation (regulatory price impact per vehicle times number of vehicles affected).

Once the parameters of Expression (7) are set, the data requirements will in general be composed of annual data on the dollar value of net and gross benefits of the regulation, industry data on the total costs associated with the regulatory activity, and the total gross revenues that the industry can hope to recover through price increases that reflect its increased regulatory costs, i.e., total regulatory price impact per vehicle times number of vehicles affected.

Note finally that for use in a cost effectiveness study, where the purpose is to choose the least-cost method among several regulatory alternatives for providing the same benefit 
level, Expression (7) yields an expression for the present discounted value of the direct resource costs of a regulation,

$$
L_{c}=\sum_{t=0}^{T} \frac{1}{(1+i)^{r}}\left\{V_{t}+R_{t}\left[\left(a^{r d}-1\right)(V-1)\right]\right\}
$$

\section{The Shadow Price of Capital}

Until now, the shadow price of one dollar or private capital, $V$, has only been generally discussed. In the Bradford article, a derivation of $V$ was included which assumes:

- that all private investment projects are of one-year duration, and

- that the savings/consumption decision with regard to gross returns on private investment is made without differentiating between depreciation and net returns [10].

Lind (1982) has recently pointed out that these two assumptions are extremely unrealistic. He has derived an alternative approach to the calculation of $V$ which allows a private investment project to depreciate over $N$ years. It assumes simply that:

- returns on private investment are in the form of an annuity over the $N$-year life of the investment, and

- all depreciation is saved, while only net returns are subjected to a savings/consumption decision.

Lind assumes that the rate of return on private investment is $r$, and that the investment pays out uniformly over $N$ years. Then the return in each year on one dollar of private investment will be

$$
A=\frac{r}{1-(1+r)^{-N}}
$$

that is, an annuity for $N$ years with a present value of one dollar discounted at $r$. Out of the stream of returns generated by one dollar of private investment (a stream of $A$ dollars in each period), $Z A$ will be saved and reinvested in each period, while ( $1-Z) A$ will be consumed, where $Z$, the fraction of $A$ reinvested, is defined as

$$
\frac{D+(A-D) \alpha^{r n}}{A}
$$

where:

$D=$ depreciation, and assuming straight line depreciation, equals $1 / N$. 
With $A$ and $Z$ defined, Lind calculates the shadow price of one dollar of private capital, $V$, as

$$
V=\frac{\sum_{t=1}^{T} \frac{1}{(1+i)^{t}} A(1-Z)}{1-\sum_{t=1}^{T} \frac{1}{(1+i)^{t}} A Z}
$$

Notice that $V$ is completely determined by four parameters, $\alpha^{r n}, r, i$, and $N$. Therefore, Expression (7) becomes an operational discounting procedure when values are set for a total of seven parameters.

\section{Application}

\section{Evaluation of Assumptions}

Under the disaggregated framework presented in Expression (7), the question of which discounting approach is correct - time preference/shadow price or opportunity cost - is subsumed within the question of reasonable values for the seven parameters. Though the task of setting values for these seven parameters appears formidable, and the $10 \%$ rule/c-t-c procedure by comparison may appear justified if for no other reason than by its simplicity, the $10 \%$ rule/c-t-c approach can be understood in this framework to imply its own set of parameter assumptions. In other words, as long as one accepts as valid

- that the government's objective in undertaking public investment projects should be to maximize the present value of the aggregate consumption stream (discounted the social rate of time preference),

- that the government faces (artificial) constraints on its investment opportunities,

- that government investment activity does displace private investment activity, and

- several simplifying assumptions listed above,

then the use of the $10 \%$ rule/c-t-c-approach (or any other discounting procedure) implies a set of assumptions about the seven parameters in Expression (7), and the validity of the procedure rests upon the validity of the parameter assumptions that are necessary to generate it. Thus, Expression (7) can be employed to develop and evaluate the conditions under which the $10 \%$ rule/c-t-c procedure (or any other procedure) is appropriate, given the statement of the government's constrained optimization problem.

The $10 \%$ Rule/Cost-to-Consumer Approach

The OMB 10\% rule is generally used in concert with a cost-to-consumer notion for calculating the direct resource costs to society of regulatory activity in the motor vehicle 
industry. The c-t-c approach is based on the premise that the direct resource costs of a regulation are best measured by the price impact of the regulation on the regulated vehicle [11]. The greater the impact on vehicle price, the more consumers will have to pay for the regulatory benefits, and hence, the greater is the cost of that regulatory program to society. In estimating the expected price impact on a vehicle, a simple mark-up factor on all variable costs of the regulation is normally used. This markup reflects industrywide information on the relationship between fixed and variable costs of production, and is defined so that when applied to industry-wide variable costs, the resulting price covers all fixed costs in the industry and provides a normal return on investment [12].

Once the expected (real) price impact on an individual vehicle is determined, the total direct resource cost of the regulation is calculated by multiplying the cost per vehicle by the number of vehicles affected after an adjustment is made to reflect the change in quantity demanded due to the vehicle price increase. The resulting real cost (and benefit) streams are then discounted by various discount rates around 10 percent.

Given the statement of the government's constrained optimization problem, the parameter assumptions under which the $\mathrm{c}-\mathrm{t}-\mathrm{c}$ measurements and the $10 \%$ rule actually reflect the true direct resource cost of the regulation to society are listed below [13]:

- $\alpha^{b n}=\alpha^{r n}=0$

- $\alpha^{b d}=a^{r d}=1$

- $r \quad=$ a range centered around 10 percent

- $i=$ unspecified

- $N=$ unspecified [14].

Under these parameter assumptions, Expression (7) can be shown to reduce to the $10 \%$ rule/c-t-c formula,

$$
\sum_{t=0}^{T} \frac{1}{(1+r)^{t}}\left\{B_{t}-C_{t}\right\}>0
$$

where $r$ is chosen from a range of values centered on 10 percent.

Since the implied parameter assumptions listed above do not include those additional assumptions necessary for the variable-cost markup simplification, Expression (9) can be thought of as an expression representing the true present discounted value of net benefits under the $10 \%$ rule/c-t-c assumptions. In practice, however, total costs of the regulation are normally approximated by a markup on variable costs leading to the formula actually used in the $10 \%$ rule/c-t-c procedure,

$$
\sum_{t=0}^{T} \frac{1}{(1+r)^{t}}\left\{B_{t}-(1+M) C_{t}^{\nu}\right\}>0
$$


where:

$M=$ the industry-wide markup factor on variable costs, and

$C_{t}^{v}=$ the total dollar value of the project's variable costs at time $t$.

Note that Expression (10) is derivable from Expression (9) only if

$$
M=\frac{\sum_{t=0}^{T} \frac{1}{(1+r)^{t}} C_{t}^{k}}{\sum_{t=0}^{T} \frac{1}{(1+r)^{t}} C_{t}^{\gamma}}
$$

where

$C_{t}^{k}=$ the total dollar value of the project's fixed costs at time $t$.

In practice, the markup $M$ is calculated from industry-wide data on the relationship between fixed and variable costs. Therefore, Expression (11) implies that the ratio of the present value of fixed costs to the present value of variable costs for the public project under consideration - the right hand side of (11) - must be the same as the ratio of annual fixed costs to variable costs, on average, for the industry as a whole - the left hand side of (11) - in order for the simplified variable cost markup proced ure to be correct within the present framework.

In short, the $10 \%$ rule/c-t-c approach captures the true direct resource costs of regulation borne by society only if, among other things,

- all of the benefits of the regulation which are viewed as depreciation are saved, while all of the net benefits are consumed,

- the pass-through of regulatory costs from industry to consumer leaves aggregate savings and investment unaffected, and

- the structure of the present value of fixed and variable costs for the public project under consideration is the same as that for the industry as a whole.

\section{Alternative Assumptions}

With the assumptions implied by the $10 \%$ rule/c-t-c approach clearly laid out, an evaluation of this discounting procedure can be carried out by evaluating the validity of those assumptions which underlie it. Where the implied assumptions appear unreasonable, alternative assumptions can be made, and an alternative discounting procedure can be derived from the new set of parameter assumptions. This procedure provides a systematic way of choosing an appropriate discounting framework by reducing the 
comparison of approaches to the evaluation of the assumptions underlying them. By making explicit what assumptions are being made, this approach also facilitates meaningful sensitivity analysis, since the uncertainty associated with each assumption can be addressed explicitly.

Clearly the specification of reasonable values for each of the parameters in this framework is not a trivial matter. Both empirical evidence and simplifying rules of thumb would ultimately play a critical role in constructing a "best estimate" or range of estimates of the appropriate discounting procedure for the costs and benefits of a regulatory project. Still, as argued above, the additional information required to properly employ this discounting framework is not in itself reason to reject it in favor of the simpler $10 \%$ rule/c-t-c approach. If the steps in developing the framework are accepted, then the $10 \%$ rule/c-t-c approach is simply one discounting procedure among many that can be generated within this framework, and its attractiveness relative to other approaches rests on the validity of the particular parameter assumptions required to generate it.

While it is beyond the scope of this article to propose appropriate values for each of the parameters in this framework, it would be useful nonetheless to examine the properties of several possible discounting procedures that are generated from reasonable values of the framework's parameters. Doing so will help to illustrate both the way in which the framework could be applied, as well as several broad differences in program treatment that can be expected if the $10 \%$ rule/c-t-c approach were replaced by alternative discounting procedures generated within this framework from reasonable parameter assumptions.

In order to generate several illustrative discounting procedures within this framework, alternative assumptions concerning the seven parameters need to be specified. The parameter values assumed for the purpose of illustration are as follows. First, if vehicle purchasers view vehicle price increases associated with regulatory activity as subtractions from disposable income, then estimates of the marginal propensity to save out of disposable income should provide a reasonable value for the parameter $a^{\text {rd }}$. For illustration, $a^{r d}$ is set at 0.10 .

Second, existing empirical evidence would support values of 0.05 and 0.12 for the parameters $i$ and $r$, respectively. While a wide range of empirical estimates for these parameters can be found, these values probably represent reasonable midpoint estimates. In addition, since the parameter $\alpha^{r n}$ represents the fraction of net returns on investment that is saved, estimates of the marginal propensity to save out of unearned income should provide a reasonable value estimate. For illustration, $\alpha^{r n}$ is set a 0.20 . To specify the shadow price of capital, $V$, a value for the average length of time over which private investment projects depreciate is also required. A value of 5 years for the parameter $N$ would probably represent a low estimate.

Finally, values for the parameters $\alpha^{b d}$ and $\alpha^{b n}$ must be specified. If consumers are thought not to differentiate between gross and net benefits of the regulatory project and treat benefits as additions to disposable income, then setting these two parameters equal 
to the marginal propensity to save out of disposable income would be reasonable. Alternatively, consumers may distinguish between gross and net benefits of the regulation, saving a portion of those benefits which represent depreciation of the regulatory capital, and consuming those benefits which represent net returns. If consumers are assumed to use regulatory benefits representing depreciation to replace the savings that were displaced by their original expenditure, then the parameter $\boldsymbol{\alpha}^{b d}$ would be set equal to $a^{r d}$ at a value of 0.10 , while $\alpha^{b n}$ would be set to zero. In the first alternative discounting procedure, the former assumption - consumers do not differentiate - is made, while the second alternative assumes that consumers do in fact differentiate.

Table 1 lists the seven parameter assumptions that generate the $10 \%$ rule/c-t-c approach and the two illustrative alternative approaches, as well as the assumption for the markup, $M$. Table 2 lists the necessary data for four hypothetical regulatory proposals. Table 3 presents the results of the application of each of the three discounting procedures to the four hypothetical programs. The four cost, benefit, and revenue streams have been chosen to illustrate several points.

The first point concerns the consequence of estimating total costs of a regulation by a markup on variable costs, as is normally done in application of the $10 \%$ rule/c-t-c procedure. To exaggerate the point, projects 1 and 2 display identical gross benefit streams and identical variable cost streams, and differ fundamentally only in their fixed cost requirements. While it is clearly the case that project 1 is superior to project 2 by any reasonable criterion, the first two rows of Table 3 reveal that the $10 \%$ rule/c-t-c procedure fails to differentiate between these two projects, since total costs for each project are approximated by applying the same industry-wide markup value to (in this

\section{TABLE 1}

Parameter Assumptions

\begin{tabular}{llll}
\hline Parameters & \multicolumn{2}{l}{ Discounting procedure } & \\
\cline { 2 - 4 } & $10 \%$ rule/ c-t-c & Alternative 1 & Alternative 2 \\
\hline$\alpha^{b n}$ & 0.0 & 0.1 & 0.0 \\
$\alpha^{r n}$ & 0.0 & 0.2 & 0.2 \\
$\alpha^{b d}$ & 1.0 & 0.1 & 0.1 \\
$\alpha^{r d}$ & 1.0 & 0.1 & 0.1 \\
$r$ & 0.1 & 0.12 & 0.12 \\
$i$ & unspecified & 0.05 & 0.05 \\
$N$ & unspecified & 5 years & 5 years \\
$M$ & 0.4 & unspecified & unspecified \\
\hline
\end{tabular}


TABLE 2

Hypothetical Project Data

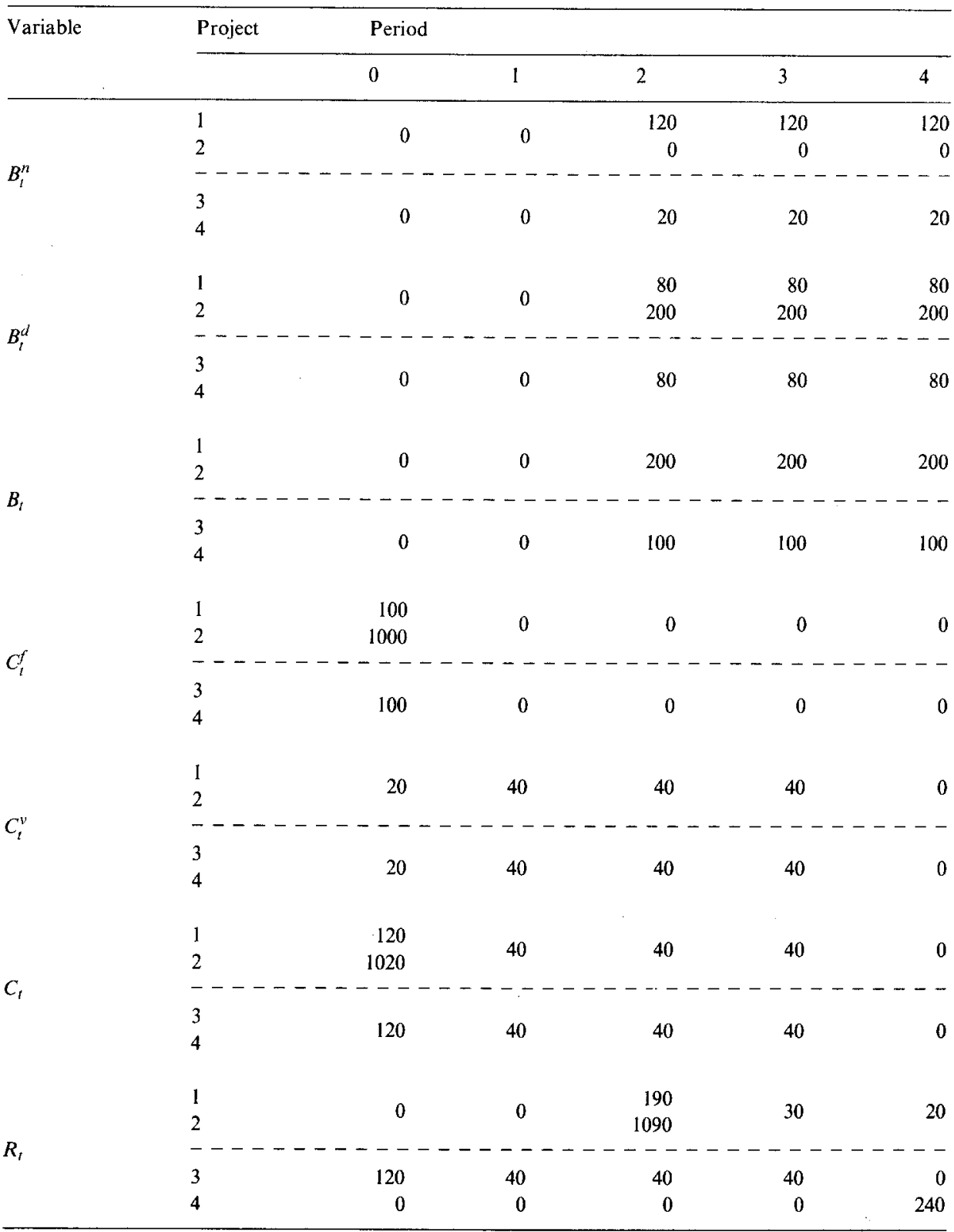


TABLE 3

$$
G_{c}-L_{c}
$$

\begin{tabular}{llcc}
\hline Project & \multicolumn{2}{l}{ Discounting procedure } & \\
\cline { 2 - 4 } & $10 \%$ rule/c-t-c & Alternative 1 & Alternative 2 \\
\hline 1 & 284.9 & 338.3 & 244.9 \\
2 & 284.9 & -1057.6 & -1057.6 \\
3 & 58.8 & 39.6 & 24.0 \\
4 & 58.8 & -45.4 & -61.0 \\
\hline
\end{tabular}

case) identical variable cost streams. Alternative procedures 2 and 3 , however, make use of total project cost data, and judge project 1 to be superior to project 2 .

In fact, as the projects have been constructed, the $10 \%$ rule/c-t-c approach would, assuming no budget constraint, lead to the initiation of both projects, while both alternative procedures would reject project 2 . The general point to be made is that, by ignoring fixed cost data and employing instead the same industry-wide markup to estimate the total costs of each project, the $10 \%$ rule/c-t-c approach has a built-in bias toward accepting projects that are relatively capital (fixed cost) intensive, and rejecting projects that are relatively intensive in variable inputs.

The second point concerns the importance of accounting for the pass-through of regulatory costs from industry to consumer. To exaggerate this point, projects 3 and 4 are identical except for the timing of revenues generated by the regulatory investment. Project 3 entails costs which are passed on to consumers immediately, while the costs associated with project 4 are not passed on until some time after they occur.

As can be seen from the last two rows of Table 3, the 10\% rule/c-t-c approach does not differentiate between these two programs. However, both the alternative discounting procedures penalize the program than involves long delays between industry expenditure and the recovery of those outlays, since private investment is being postponed for a longer period of time. As constructed, the $10 \%$ rule/c-t-c procedure leads to acceptance of both projects, while the two alternative procedures accept only project 3 .

The general point here is that, unlike the alternative discounting procedures, the $10 \%$ rule/c-t-c procedure is not sensitive to differences in the timing of the cost pass-through process. Moreover, this property will be common to all discounting procedures generated within the framework, as long as $a^{\text {rd }}<1$. Thus, this point will be robust to reasonable sensitivity analysis.

These two points illustrate broad differences in program treatment that could be expected if the $10 \%$ rule $/ \mathrm{c}-\mathrm{t}-\mathrm{c}$ procedure were to be replaced by a discounting procedure generated within this framework which 
- abandons the variable cost markup approximation for total regulatory costs, and

- allows consumers to consume a portion of the regulatory benefits representing depreciation.

However, more specific consequences of the implementation of this framework can not be outlined without more specific information on the actual parameter assumptions to be employed. Of special concern here is the shadow price of capital, $V$, which Lind (1982) has shown to be quite sensitive to specification of the parameters from which it is determined.

Thus, of central importance for the implementation of this framework are consensus estimates for the seven parameters, in addition to confidence intervals which reflect the uncertainty associated with each parameter value. Consensus estimates can be employed to develop a preferred discounting procedure for the costs and benefits of a regulatory proposal, while confidence intervals will serve to delineate a range of alternatives to be employed in sensitivity analysis. Given this information, a meaningful and systematic analysis of the costs and benefits of industry regulation can be undertaken.

\section{Conclusions}

A methodology has been developed to facilitate the systematic comparison of alternative discounting procedures for the costs and benefits of industrial regulatory activity. Within this framework, the cloice between discounting procedures is reduced to a choice between assumptions about various economic and financial parameter values.

The framework has been employed to evaluate the parameter assumptions implied by the discounting approach currently used by regulatory agencies in their impact analyses for regulation in the motor vehicle industry. This application illustrates the way in which the framework could be employed both to evaluate current discounting procedures and to develop alternative discounting approaches which reflect explicitly both underlying assumptions and the uncertainty associated with those assumptions.

\section{Acknowledgements}

The authors wish to thank the Motor Vehicle Manufacturers Association (MVMA) for support of this work through unrestricted gift funds. They also thank the members of the MVMA Engineering Strategic Planning Committee and Muriel J. Converse, E. W. Eckard, Jr., Daniel H. Hill, and Daniel L. Rubinfeld for their helpful suggestions. The responsibility for any errors in this report lies entirely with the authors.

\section{Notes}

I In order to avoid issues involving project risk, it is assumed that all public and private investments are riskless.

2 For simplicity, it is assumed throughout the article that neither the firm nor the government faces a budget constraint. 
3 An extension of this line of reasoning leads easily to the conclusion that the proportion of project benefits reinvested will also affect the relative valuation of a public project, and hence provides another motivation for the inclusion of both $i$ and $r$ in the discounting framework for public projects.

4 To the extent that international capital flows make the domestic supply of capital perfectly elastic, government investment funds will not displace private domestic investment, and the dollar value of the costs and benefits of such projects could be discounted at the social rate of time preference. It is assumed throughout this paper that rationing in the domestic capital market does in fact occur. Such an assumption underlies the public sector discounting literature upon which this paper is based.

5 It should be emphasized that government regulation of private industry, which is the focus of this paper, is not a private sector undertaking. The relevant distinction between private-and public-sector undertakings is in what sector the decision is made undertake the project, not in what sector the project is undertaken. Thus, regulatory projects undertaken by private industry are public projects carried out by the private sector.

6 Strictly speaking, equity and efficiency goals can be pursued independently of one another only in a first-best environment - see, for example, Tresch (1981).

7 As discussed previously, when no (artificial) limitations on public investment are assumed, only the rate of return on private investment is relevant, since this rate of return is now the oppurtunity cost of all public investment funds. See, for example, Mishan (1976).

8 Regulatory costs incurred by the government are excluded from this analysis for simplicity.

9 It is assumed for simplicity that the projects foregone by the industry have the same characteristics as investment projects, on average, in the economy as a whole, e.g., same average length.

10 These assumptions allow Bradford to conclude that the shadow price of capital, $V$, is fairly close to one, and consequently that discounting unadjusted costs and benefits of government investment projects at the social rate of time preference represents a reasonable rule of thumb. However, with the likelihood that $V$ is significantly greater than one as Lind argues, the rule of thumb suggested by Bradford becomes less attractive.

11 Other related costs, such as those due to decreased engine efficiency, are also counted but, for simplicity, they will be ignored here.

12 An additional markup from wholesale to retail is also employed to cover dealer overhead.

13 Note that these assumptions generate the Sjaastad and Wisecarver result that the discount rate is a weighted average of the social rate of time preference and the opportunity cost of capital. In this particular case, the weight on the opportunity cost of capital is unity, while the weight on the social rate of time preference is zero. An alternative, but trivial, way to generate the $10 \%$ rule/c-t-c procedure from this framework is to assume that $i=r=0.10$ so that the shadow price of capital, $V$, is one.

14 For $N$ greater than one, this set of assumptions will generate a discounting procedure identical to Expression (9) with the exception of one insignificant adjustment which is developed in Sjaastad and Wisecarver.

\section{References}

Arrow, K. J. (1966). "Discounting and public investment criteria," in A.V. Kneese and S. C. Smith (eds.), Water Resources Research. Baltimore: Johns Hopkins.

Baumol, W. J. (1968). "On the social rate of discount," American Economic Review 58: 778-802.

Bradford, D. F. (1975). "Constraints on government investment opportunities and the choice of the discount rate," American Economic Review 65: 887-899.

Diamond, P. (1968). "The opportunity costs of public investment: Comment," Quarterly Journal of Economics 82: 682-688.

Diamond, P. and Mirrlees, J. (1976). "Private constant returns and public shadow prices," Review of Economic Studies 43: 41-47.

Feldstein, M. S. (1972). "The inadequacy of weighted discount rates," in R. Layard (ed.), Cost-Benefit Analysis. Harmondsworth, Middlesex, England: Penguin Books.

Harberger, A. C. (1972). "The opportunity costs of public investment financed by borrowing," in R. Layard (ed.), Cost-Benefit Analysis. Harmondsworth, Middlesex, England: Penguin Books. 
Lind, R. C. (1982). "A primer on the major issues relating to the discount rate for evaluating national energy options," in K. Arrow and R. C. Lind (eds.), Discounting for Time and Risk in Energy Policy. Washington, DC: Resources for the Future, Inc. and Baltimore: Johns Hopkins, pp. 21-94.

Marglin, S. A. (1963a). "The social rate of discount and the optimal rate of investment," Quarterly Journal of Economics 77: 95-111.

Marglin, S. A. (1963b). "The opportunity costs of public investment," Quarterly Journal of Economics 77 : 274-289.

McKean, R. N. (1958). Efficiency of Government through Systems Analysis. New York: John Wiley \& Sons. Mishan, E. J. (1976). Cost-Benefit Analysis: An Introduction. New York: Praeger.

Sandmo, A. and Dreze, J. H. (1971). "Discount rates for public investment in closed and open economics," Economica 38: 395-412.

Sjaastad, L. A. and Wisecarver, D. L. (1977). "The social cost of public finance," Journal of Political Economy 85: $513-547$.

Tresch, R. W. (1981). Public Finance: A Normative Theory. Plano, TX: Business Publications, Inc.

U.S. Office of Management and Budget (1981). Interim Regulatory Impact Analysis Guidance. 